\title{
A Comparative Study of the Status of Oxidative Stress Markers, Antioxidant Enzymes in Alcoholic Hepatitis Patients
}

\author{
Authors \\ Sanjay Bhatt ${ }^{1}$, M. Itagappa ${ }^{1}$, R.M.Shinde ${ }^{2}$, Bindu Sati ${ }^{2}$, J. B. Gogoi ${ }^{2}$, Jyoti Batra $^{3}$ \\ ${ }^{1}$ Department of Biochemistry, RMRI, Bareilly, UP, VCSG GIMSR, Srinagar \\ ${ }^{2}$ Department of Medicine, VCSG GIMSR, Srinagar, Garhwal \\ ${ }^{3}$ Department of Biochemistry, Santosh Medical College \& Hospital, U.P \\ Corresponding Author
}

Sanjay Bhatt

Assistant Professor, Department of Biochemistry, RMRI, Bareilly

Email-sanjay_bhatt25@yahoo.com

\section{ABSTRACT}

Background: The exact pro-oxidant and antioxidant status in alcoholic hepatitis is still not clear.

Material \& Methods: The present study was conducted in Department of Biochemistry, RMRI, Bareilly and Santosh medical college \& Hospital. 35 alcoholic hepatitis patients were subjected to detailed clinical examination and laboratory investigations and the results were compared with 35 controls. Blood samples were collected for oxidative stress parameters. It was observed that there was a significant increase in activities of SOD, GPX, MDA and Catalase activity in patients with alcoholic hepatitis when compared to controls.

Results: Results of our study depict higher oxygen free radical production, evidenced by elevated levels of MDA and decreased levels of GSH, ascorbic acid, vitamin-E and Catalase activity, supporting the evidence of oxidative stress in alcoholic hepatitis patients. Increased activities of antioxidant enzymes might be a compensatory regulation of body in response to increased oxidative stress. Decreased concentrations of antioxidant vitamins support the hypothesis that alcoholic hepatitis is an important causative factor in pathogenesis of lipid peroxidation.

Conclusion: These data reveal that antioxidant defense mechanisms might be impaired in patients with alcoholic hepatitis. These findings also provide a theoretical basis for development of novel therapeutic strategies, such as antioxidant supplementation.

Key Words: Superoxide dismutase (SOD), glutathione peroxidase, catalase, alcoholic hepatitis.

\section{INTRODUCTION}

Alcoholic Hepatitis is an alcohol induced disease with genetic, psycho-social and environmental factors influencing its development and manifestations. The disease is often progressive and is considered to be a major cause of morbidity and mortality. In recent years, oxidative stress has been implicated in the path physiology of a large number of disease or disorders which are initiated and /or exacerbated by pro-oxidants such as 
various drugs including alcohol and food additives. Besides, ingested alcohol produces striking metabolic imbalances in the liver. It leads to the formation of reactive oxygen species (ROS).Inadequate removal of ROS may cause cell damage by attacking membrane lipids, proteins and inactivating enzymes thus mediating several forms of tissue damage. At present, except for the abstinence of alcohol abuse, there is no effective modality of either prevention or treatment. The incidence of Alcohol Hepatitis is increasing day by day specially in the developing countries including India. The present study was planned with the objectives to investigate the oxidative damage and the efficiency of antioxidant defense system in patients of alcoholic hepatitis in the socioeconomic belt of Srinagar, Garhwal, Uttarakhand.

\section{MATERIALS AND METHODS}

Thirty five clinically, pathologically proven fresh cases of alcoholic hepatitis (group A; age: 21-45 years) and 35 clinically healthy volunteers of either sex (group B; age: 17-40 years) were included in this study. Only minimal and moderately advanced patients of alcoholic hepatitis were included in the present study (13). All participants were synchronized for one week with diurnal activity from about 6:00 to about 22:00 hrs. And nocturnal rest. All subjects took their usual (although not identical) meals three times daily; breakfast around 8:30 a.m., lunch around 13:30 p.m. and dinner around 20:30 p.m., without any change in their usual fluid intake. The burden of environmental temperature and pollution, if any, was common to all participants. Prior to the blood sample collection, the participants refrain from taking any drugs/preparation that would affect or alter the oxidative stress, its defensive mechanism, level and rhythm. Six millilitres of blood was collected from each subject at fixed time points for one complete 24 hour cycle, at 06:00, 12:00, 18:00 and 00:00 hrs. in plain and sterile vials containing heparin as anticoagulant. The plasma was separated and analyzed for lipid peroxides in terms of malondialdehyde (MDA) (14). The haemolysate was prepared from the red cells and used for the measurement of the activities of enzymes superoxide dismutase (SOD), catalase (CAT) and glutathione peroxidase (GPx) $(15,16,17)$. Data were evaluated by conventional statistical analyses and by the single- and population-mean cosinor procedures $(18,19)$.

\section{RESULTS \& OBSEVATIONS}

Table-1 Distribution of patients of Alcoholc hepatitis according to groups.

\begin{tabular}{|l|l|}
\hline Group & Number of Patients \\
\hline A & 35 \\
B & 35 \\
\hline Total & 70 \\
\hline
\end{tabular}

Table-2 Serum Superoxide Dismutase (SOD), Malondialdehyde (MDA), Glutathione Peroxidase (GPx) and Catalase levels amongst normal healthy individuals and patients of alcoholic hepatitis.

\begin{tabular}{|l|l|l|}
\hline Parameters & Control $(\mathrm{n}=35)$ & Patients $(\mathrm{n}=35)$ \\
\hline SOD & $20.91 \pm 0.05$ & $16.05 \pm 0.09$ \\
MDA & $2.30 \pm 0.03$ & $2.95 \pm 0.03$ \\
GPx & $4.21 \pm 0.03$ & $2.90 \pm 0.03$ \\
Catalase & $15.55 \pm 0.04$ & $12.18 \pm 0.08$ \\
\hline *P $\left.<0.001^{\prime}\right]$ &
\end{tabular}

\section{DISCUSSION}

These data reveal that antioxidant defense mechanisms might be impaired in patients with alcoholic hepatitis. These findings also provide a theoretical basis for development of novel therapeutic strategies, such as antioxidant supplementation.

A marked circadian variation in plasma MDA level was recorded in healthy Indians and alcoholic hepatitis patients with significant amplitude and acrophase around 16:21 and 17:12 respectively. The circadian acrophase of plasma MDA levels occurred around 50 minutes later in patients in comparison to healthy controls; however, there was no significant difference in the MESORS of the two groups. The circadian amplitude tends to be increased in alcoholic hepatits patients in comparison to the healthy 
volunteers. There are no reports regarding circadian variations of circulating lipid peroxides in alcoholic hepatitis patients under tropical conditions. A statistically significant circadian rhythm was recorded in SOD, CAT and GPx concentrations in clinically healthy subjects and alcoholic hepatitis patients. SOD activity was found to be maximum at 06:00 hrs. and minimum at 00:00 hrs. in patients. Moreover, the activity was noticed to be decreased at all sampling hours during a 24-hour sleep-awake period in patients in comparison to their healthy counterparts. The circadian acrophase occurred 30 minutes later in patients as compared to healthy volunteers. Similarly, CAT activity was also noticed to be reduced at all collection hours in patients with decreased MESOR and circadian amplitude. The circadian acrophase occurred around 1 hour and 30 minutes later in patients. GPx activity further decreased at all collection hours in alcoholic hepatitis patients with maximum activity at 00:00 and minimum at 12:00. The MESOR and circadian amplitude decreased markedly. Moreover, there was maximum swing and altered rhythm in the activity of this important antioxidant enzyme where the circadian amplitude was found to occur about 6 hours and 30 minutes later in patients in comparison to healthy subjects. The decreased concentration of measured antioxidant enzymes in alcoholic hepatitis patients could probably be associated with oxidative stress and/or decreased antioxidant defense mechanism. GPx activity, found to be decreased at all sampling hours in patients in comparison to healthy subjects, clearly exhibited an imbalance between oxidant and antioxidant defensive systems in the human body under such pathological situations.

\section{REFERENCES}

1. Aebi, H. and Suter, H. "Protective function of reduced glutathione against the effect of pro-oxidative substances and of irradiation in the red cell'. In Flone, L.,Besnhar, H.C.
Ceditors,. Glutathione. Stuttgart: Georg Thieme; 192 - 199, 1974.

2. Ahmad R, Tripathi A K, Tripathi P, Singh R, Singh S, Singh R K. "Studies on lipid peroxidation and non-enzymatic antioxidant status as indices of oxidative stress in patients with chronic myeloid leukemia".Singapore Med J; 51(2) : 110, 2010.

3. Alcohol and Health. (U.S. department of Health and Services), Seventh Special Report to the U.S. Congress. 1990.

4. Bergmeyer HU, Bernt E. Glutamate oxaloacetate transaminase; Glutamate pyruvate transaminase. In: Methods of Enzymatic Analysis (Ed. Bergmeyer HU) Academic Press, New York, pp. 1963, 837-853.

5. Beers RF, Sizer IW. A spectrophotometric method for measuring the breakdown of hydrogen peroxides by catalase. J BiolChem; 1952; 195: 133-140.

6. Breus, T.K.,Cornelissen, G., Halberg, F. and levitin, A.D.,"Temporal associations of life with solar and geophysical activity" Ann. Geophys; 13:1211 - 1222, 1995.

7. Breus, T.K.,Halberg, F. and Cornelissen, G., "Influence of solar activity on the physiological rhythms of biological system". Biofizika (Russian); 40(4):737 7481995.

8. Bunning, E.,"The physiological clock; Circadian rhythms and biological chronometery. $3^{\text {rd }}$ edn. Springer, Berlin, Heidelberg, New York, 1973.

9. Bunning E. "The physiological clock; endogenesis; diurnal rhythms and biological chronometry". Academic, New York, 1964.

10. Conroy, R.T.W.L and Mills, J.N. "Human circadian rhythms". Churchill,London 1970.

11. Chronomics and Chronobiology in health and disease. Singh RK.Indian Journal of clinical Biochemistry. 24(4) 319-323, 09. 
12. Das SK, Nayak P, Vasudevan DM. Biochemical Markers for Alcohol Consumption. Ind J ClinBiochem. 2003; 18(2): 111-118.

13. Das SK, Vasudevan DM. Monitoring oxidative stress in patients with nonalcoholic and alcoholic liver diseases. Ind J ClinBiochem. 2005; 20(2). (In Press)

14. Frienhel, N., Aky, R.A, Singer, D.L, Cohen, A.K.(1985). Alcohol hypoglycemia IV. Current concepts of its pathogenesis. Diabetes 4, 350-361.

15. Goldberg, M.D.; and Spooner, J.R.. In: Methods of Enzymatic Analysis (ed. Bergmayer), Vol. III, $3^{\text {rd }}$ edn. Academic Press, Inc., Florida, 1983; pp. 258-265.

16. Grant BF, Harford TC. Epidemiology of alcoholic liver disease. Semin Liver Disease 1988; 8:12-25.

17. Gupta S, Pandey R, Katyal R, Agarwal HK, Agarwal SK. Lipid peroxide and antioxidant status in alcoholic liver disease. Ind J ClinBiochem 2005; 20(1): 67-71.

18. Halberg, F. Lornelissen, G.,Bakken, E., "care giving merged with chronobiologic outcome assessment, research and education in health maintenance organization”. Prog. Clin Biol. Res; 3418: 491 - 549, 1990.

19. Halberg, F., "Chronobiology". Ann. Rev Physiol; 31; 675 - 725; 1969.

20. Halliwell; B,. Antioxidants in human health and disease". Annu. Rev. Nutr; 16: $33-50,1996$.

21. Halliwell, B.,Gutteridge, J.M.C, "Free radicals in biology and medicine" $3^{\text {rd }}$ ed. Oxford kingdom, Oxford University press, 1999.

22. Harman, D., "Role of free radicals in aging and disease". Annals of New York Academy of Sciences; 673: 126 - 141; 1992.
23. Hans, E. and Halberg, F., "The Circadian time structure". NATO Adv. Study Inst [D]: $47-94,1980$.

24. Halberg, F. Quo vadis basic and clinical chronobiology: promise for health maintenance. Am J Anat; 168:543-94, 1983.

25. Haus E, Touitou Y. "Chronobiology in laboratory medicine". In: Touitou Y, Haus E, editors. Biologic rhythms in clinical and laboratory medicine. Springer-Verlag; Berlin, Heidelberg, New York: pp. 673708, 1992.

26. Halberg, F. "Implications of biologic rhythms for clinical practice". Hosp Pract.; 12:139-49, 1977.

27. Hirnwich, H.E., Nahum, L.H., Pakieten, N., Fazekas, J.F., DU Bots, H. (1982). Effects of alcohol on metabolism. Am.J.Physiol. 101, 57-68.

28. Irshad M, Chaudhuri PS. "Oxidantantioxidant system: role and significance in human body". Indian J ExpBiol; 40:1233-9, 2002.

29. Jose C. Fernández-Checa, Ph.D., Neil Kaplowitz, M.D., Anna Colell, and Carmen García-Ruiz, Ph.D. Oxidative Stress and Alcoholic Liver Disease: RESEARCH UPDATE.

30. Kolanjiappan, k. Manoharan, S. and Kayalvizhi, M. (2002).Measurement of erythrocyte lipids, lipid peroxidation, antioxidants and osmotic fragility in cervical cancer patients. Clin. Chin. Acta. 326, 143-149.

31. Langseth, L, "Oxidants; antioxidants and disease prevention". Belgium, International Life Science Institute, 1996.

32. Liber CS. Alcohol and liver: metabolism of alcohol and its role in hepatic and extrahepatic diseases. Mt Sinai J Med 2000; 67 (1): 84-94.

33. Liber CS. Biochemical and molecular basis of alcohol induced injury to liver and 
other tissues. N Eng J Med 1988; 319:1639-1650.

34. Lieber CS. Ethanol metabolism, cirrhosis and alcoholism. Clin. Chim. Acta1997; 257(1): $59-84$.

35. McCord. J.M and Fridovich, I., "Superoxide dismutase: an enzyme functions for erythrocuprin". J. Biolchem, 24: 6049 - 6055, 1969.

36. Natelson. S., "Techniques of clinical chemistry". $3^{\text {rd }}$ ed., Publisher charles, C., Thomas, USA, 286, 751 and 162, 1971.

37. OhKawa, H., Ohishi, N. and Yagi, K., "Assay for lipid peroxidase in animal tissues by thiabarbituric reaction". AnnalBiochemi; 95: 151 - 157, 1979.

38. Pagila, D.E Valentine, W.N., "Studies on quantitative and qualitative characterization of erythrocyte glutathione peroxidase". J Lab clinMed; 2; 158 - 169, 1967.

39. Roe JH, Kuther CA. The determination of ascorbic acid in whole blood and urine through the 2,4-dinitrophenyl hydrazine derivative of dehydro ascorbic acid. J Biol Chem. 1943; 147: 399-401.

40. R. Singh, R. K. Singh, R. K. Singh, A. K. Tripathi, G. Cornélissen, O. Schwartzkopff, K. Otsuka, and F. Halberg.Chronomics of circulating plasma lipid peroxides and anti-oxidant enzymes and other related molecules in cirrhosis of liver. Biomed Pharmacother. 2005 October; 59(Suppl 1): S229-S235.

41. Sie H: Oxidative stress: from basic research to clinical application. Am J Med 1991; 9: 31-38.

42. Singh R, Singh RK, Mahdi AA, et al. "Circadian periodicity of plasma lipid peroxides and other anti-oxidants as putative markers in gynecological malignancies”. In Vivo; 17:593-600, 2003.
43. Singh R, Singh RK, Tripathi AK, et al. "Chronomics of circulating plasma lipid peroxides and anti-oxidant enzymes and other related molecules in cirrhosis of liver". In the memory of late Shri Chetan Singh. Biomed Pharmacother; 59 supply 1:S229-35, 2005.

44. Sherlock, S.(1995). Alcohol and the liver. In: Sherlock S. Diseases of the liver and biliary system. 6th ed. Blackwell publications London, pp 385-403. 